\title{
Unusual behavior of oviposition and development of Sitophilus zeamais (Coleoptera: Curculionidae) in peach and apple fruits
}

\author{
Sandro Daniel Nörnberg • Anderson Dionei Grützmacher • \\ José Mauricio Simões Bento • Cornel Adler • Dori Edson Nava
}

Received: 25 May 2017 / Accepted: 23 January 2018

(C) Springer Science+Business Media B.V., part of Springer Nature 2018

\begin{abstract}
The maize weevil Sitophilus zeamais Motschulsky, 1855 (Coleoptera: Curculionidae) is a worldwide pest on stored products, as maize, wheat and rice grains. However, in South Brazil, these weevils have been found attacking fruits in field conditions. It was reported that adults attack fruits to feeding, but there was no information of
\end{abstract}

S. D. Nörnberg $(\bowtie) \cdot$ D. E. Nava

Laboratório de Entomologia, Embrapa Clima Temperado, Programa de Pós-graduação em Fitossanidade - FAEM/UFPel, BR 392, Km78, Caixa Postal 403, Pelotas, Rio Grande do Sul 96001-970, Brazil

e-mail: sandro.nornberg@partamon.com

D. E. Nava

e-mail: dori.edson-nava@embrapa.br

\begin{abstract}
A. D. Grützmacher
Laboratório de Manejo Integrado de Pragas (LabMIP), Programa de Pós-graduação em Fitossanidade, Departamento de Fitossanidade, Faculdade de Agronomia Eliseu Maciel (FAEM), Universidade Federal de Pelotas (UFPel), Campus Capão do Leão, Caixa Postal 354, Pelotas, Rio Grande do Sul 96010-900, Brazil

J. M. S. Bento

Laboratório de Ecologia Química e Comportamento de Insetos, Departamento de Entomologia e Acarologia, Escola Superior de Agricultura Luiz de Queiroz, Universidade de São Paulo, Avenida Pádua Dias, 11, CEP 13418-900, Piracicaba, São Paulo, Brazil

C. Adler

Federal Research Centre for Cultivated Plants - Julius Kühn Institut, Institute for Ecological Chemistry, Plant Analysis and Stored Product Protection, Königin-Luise-Str. 19, D-14195 Berlin, Germany
\end{abstract}

oviposition and larval development on these hosts. Furthermore, due to monitoring apple orchards, was observed that some fruits showed distinct kind of punctures, suggesting a oviposition by these weevils. The present study reports first record an unusual behavior of $S$. zeamais by oviposition and larval development in peach and apple fruits. The study was conducted in laboratory conditions (temperature: $25 \pm 1{ }^{\circ} \mathrm{C}$, RH: $70 \pm 10 \%$ and photophase of $14 \mathrm{~h}$ ). Peach and apple fruits were offered to $S$. zeamais females. The oviposition and duration of immature stages in peach were measured in fruits and in corn grains, used as control observation. The oviposition and larval development occurred in peach and apple fruits, with a development until to adult. The average of egg-to-adult was $47.4 \mathrm{~d}$ in peach and and $45.1 \mathrm{~d}$ apple fruits, respectively, while in corn grains, its natural host, the duration was $38.2 \mathrm{~d}$. These results show that the damage caused by $S$. zeamais in peach and apple fruits may be due to oviposition and the development of immature stages. So, the novelty is in demonstrating that the maize weevil does not just feed as an adult opportunistically on the fruits, but can complete a full life cycle using fresh fruits.

Keywords biology . maize weevil $\cdot$ potential pest $\cdot$ host adaptation

Weevils of the Sitophilus genus (Coleoptera: Curculionidae) are distributed worldwide and considered important pests of stored grain (Danho et al. 2002; Plarre 
2010). In Brazil, two species are considered pests, Sitophilus zeamais Motschulsky, 1855 and Sitophilus oryzae (Linnaeus 1763) (Corrêa et al. 2013). These insects attack grains as rice, wheat, maize and several other commodities and prefer whole grains for breedings, but have been also reported to feed on several other products, as pet food and pastas (Longstaff 1981; Murata et al. 2008).

The maize weevil, $S$. zeamais is a primary field to store pest, that starts to infest maize crop in the field when the grain are ripening (Adedire 2001) causing damage and economic losses. Although are usually associated with these hosts, $S$. zeamais also are reported to infesting fresh fruits, as recorded in peach (Prunus persica), apple (Malus domestica), and grape fruits (Vitis sp.) plantings from Brazil (Botton et al. 2005a; Nörnberg et al. 2013). In southern Brazil, S. zeamais was reported in apple orchards causing damage to fruits at the orchards conditions (Lorenzato and Grellmann 1987). In grape, the maize weevil has been reported as highly harmful in vineyards of wine grapes in compact bunches (Botton et al. 2005b; Hickel and Schuck 2005). In peach orchards, infestation occurs only in ripe fruits, from early November (early cultivars) to February (late cultivars) (Nörnberg et al. 2013).

The damages caused by adults of $S$. zeamais in peach fruits were attributed to the feeding habit, where the insect pests pierce the fruit skin and feed on its pulp, causing direct damage, such as fruit drop (Botton et al. 2005a; Salles 1998). Additionally, the fruit damage enables infestation by other species, which are not capable of infesting sound fruits, or indirect damage by favoring the occurrence of phytopathogens, as brown rot in peach, caused by the fungus Monilinia fructicola (Wint.) (Honey, 1928) (Helotialis: Sclerotiniaceae) (Salles 1998).

However, there are no information reported to oviposition and larval development of $S$. zeamais on fruits. Thus, this study was carried out in laboratory conditions to demonstrate the oviposition and the larval development of $S$. zeamais in peach and apple fruits.

A colony of $S$. zeamais was maintained in the laboratory, at $25 \pm 1{ }^{\circ} \mathrm{C}$, RH $70 \pm 10 \%$ relative humidity and photophase of $14 \mathrm{~h}$, in organic yellow maize kernels in glass boxes ( 21 ). The colony started by weevils collected on peach fruits in commercial orchards. The identification of $S$. zeamais was carried out based on Halstead (1963). The weevils used in this study were from 3rd generation held in corn grains.

To evaluate the oviposition and immature stage development of $S$. zeamais, 100 peach fruits (variety Eldorado) and 100 apple fruits (variety Eva) were used, which collected at organic orchards in Pelotas, Rio Grande do Sul State, southern Brazil (31 $37^{\circ} 23^{\prime \prime}$ S, $\left.52^{\circ} 36^{\prime} 16^{\prime \prime} \mathrm{W}\right)$. Corn grains was used as control. In order to eliminate contaminating microorganisms, the fruits ( $\sim 20$ days before harvest) were washed with a solution with distilled water and sodium hypochlorite (NaOCL) at $1 \%$ in immersion for $5 \mathrm{~min}$ and subsequently were washed with distilled water and kept at room temperature for drying.

Four mated females, with 15-day-old, were placed on the fruit surface and delimited by a small cage $(25 \mathrm{~mm}$ wide and $12 \mathrm{~mm}$ high) to limit weevil dispersion and to facilitate the localization of the eggs on the fruits. The females were preliminarily selected by the morphological characteristics, specifically by the rostrum characteristics. Subsequently, for the sex confirmation, the weevils were dissected and identified by specific differences on male and female genitalia. Both were carried out in accordance with the method previously described by Halstead (1963). After $24 \mathrm{~h}$ of exposure to the fruits the weevils were observed on the cages for several days until oviposition occurred. In order to describe the rostrum and the chewed holes diameters in the fruits, a stereoscopic microscope with a $10 \mathrm{x}$ micrometric ocular and $6.3 \mathrm{x}$ objective lenses were used.

The evaluation of immature stages was conducted observing the initial puncture in the fruits made by females and removing the area with a stylet, using a stereoscopic microscope (with 32 times magnification) and the observations of the life stages were carried out in accordance with the method previously described by O'Donnell (1967). Daily, a sample of two fruits and 10 grains were evaluated to observe and determine the developmental stage of $S$. zeamais and consequently estimate the duration of each developmental stage. Oviposition and development of $S$. zeamais in peach and apple fruits were demonstrated graphically by photographic records and data on the average duration of each developmental stage were expressed in days.

We observed that $S$. zeamais females in contact with the peach and apple fruits exhibited initially a feeding habit by uses strong mandibles to chew a small hole in the fruit exocarp. In this bioassay conditions, the oviposition was observed only after a period of three to five days, unlike in corn grain where oviposition occurred on the first day.

Feeding habits of weevils was characterized by punctures of varied sizes, with holes ranging from the same diameter as the rostrum $(\sim 0.25 \mathrm{~mm})$ to diameters large 
enough for a weevil to enter. The damage caused by oviposition of $S$. zeamais in peach and apple fruits was characterized by the formation of small holes, corresponding to the diameter of the rostrum of a female, and laid two eggs on average, which were seals the hole with mucilaginous secretions (Figs. 1a and 2a). The characteristics of oviposition observed in fruits were similar to those observed in grain kernels, which females searched for a suitable region in the grain for oviposition, bored a hole with the mandibles, laid their egg and covered them with a mucilaginous secretions from her ovipositor (Longstaff 1981).

However, after $48 \mathrm{~h}$ of oviposition in the place where the egg was deposited in both peach and apple fruits, we observed the formation of a circle $(\sim 0.25 \mathrm{~mm}$ in diameter) where the fruit exocarp was necrosed (dark brown color) (Figs. $1 \mathrm{~b}$ and $2 \mathrm{~b}$ ). This formation of the circle of necrotic cells was similar to what occurs in damage caused by the feeding habit, however, the holes for oviposition were shallower, that is, of the size of eggs (between 0.8 to $1.0 \mathrm{~mm}$ ) (Fig. 2c). Eggs of the genus Sitophilus have an average size of $0.76 \times$ $0.27 \mathrm{~mm}$ (Lecato and Flaherty 1974).

The differentiation between the hole for oviposition and the hole caused by puncture of exocarp was only possible with the use of some equipment to magnifies the images (Figs. 1b and 2b). In addition, under field conditions, weevils concentrate mainly in the peduncle insertion region (Nörnberg et al. 2013) where they feed and probably perform oviposition, hindering the
Fig. 1 Oviposition and development of the immature stages of Sitophilus zeamais in peach fruit: Oviposition (a, b); gallery formation in peach pulp (c); larva (d); larvae in the last instar (e, f); pupa (g, h). Temperature $25 \pm 1^{\circ} \mathrm{C}$, RH 70 $\pm 10 \%$ and photophase of $14 \mathrm{~h}$

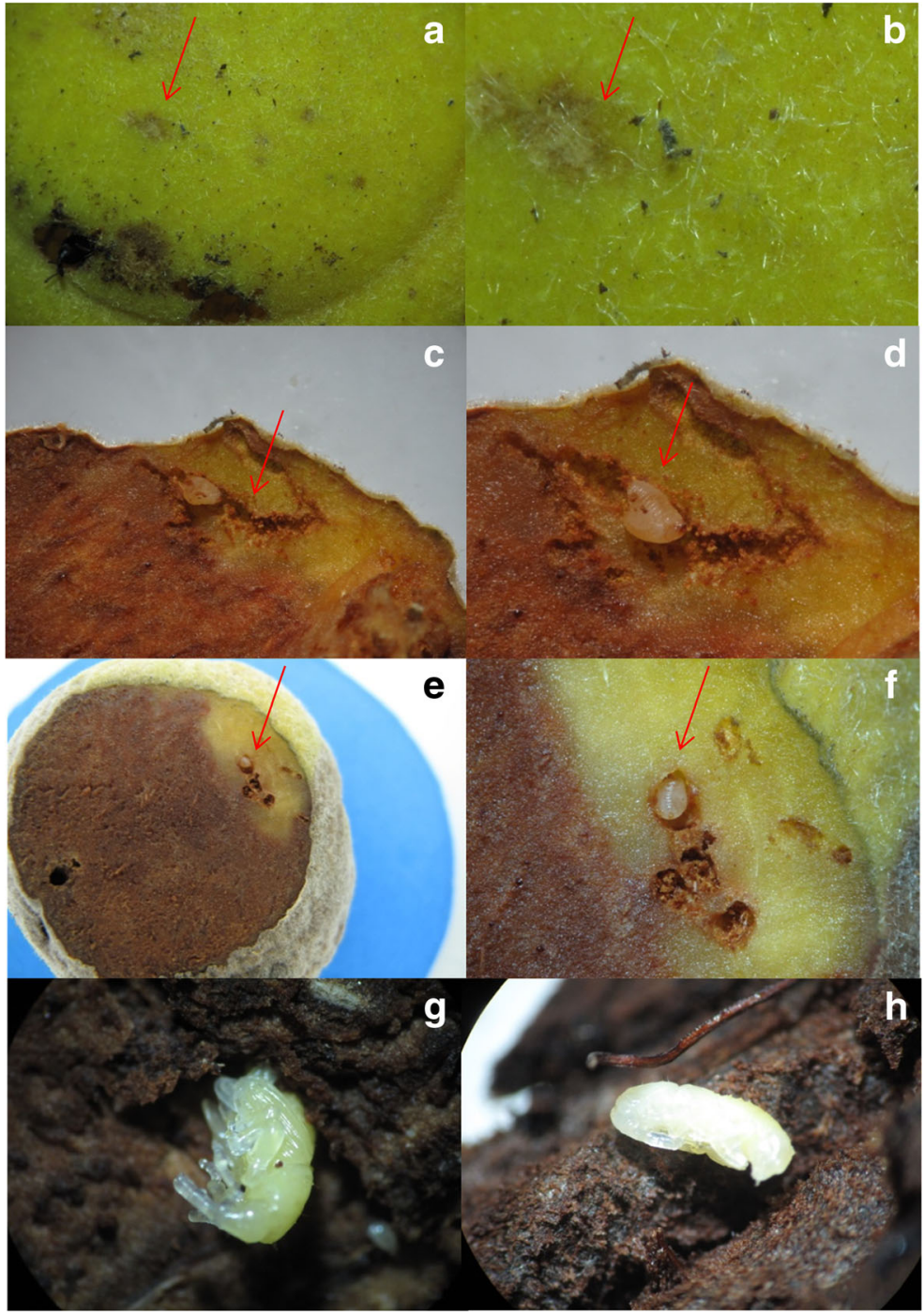


Fig. 2 Oviposition and development of the immature stages of Sitophilus zeamais in apple fruit: Oviposition (a, b); oviposition site (c); eggs (d); larva (e); gallery formation in apple pulp (f, g); larva in the last instar (h); pupa (i, j). Temperature $25 \pm$ $1{ }^{\circ} \mathrm{C}, \mathrm{RH} 70 \pm 10 \%$ and photophase of $14 \mathrm{~h}$

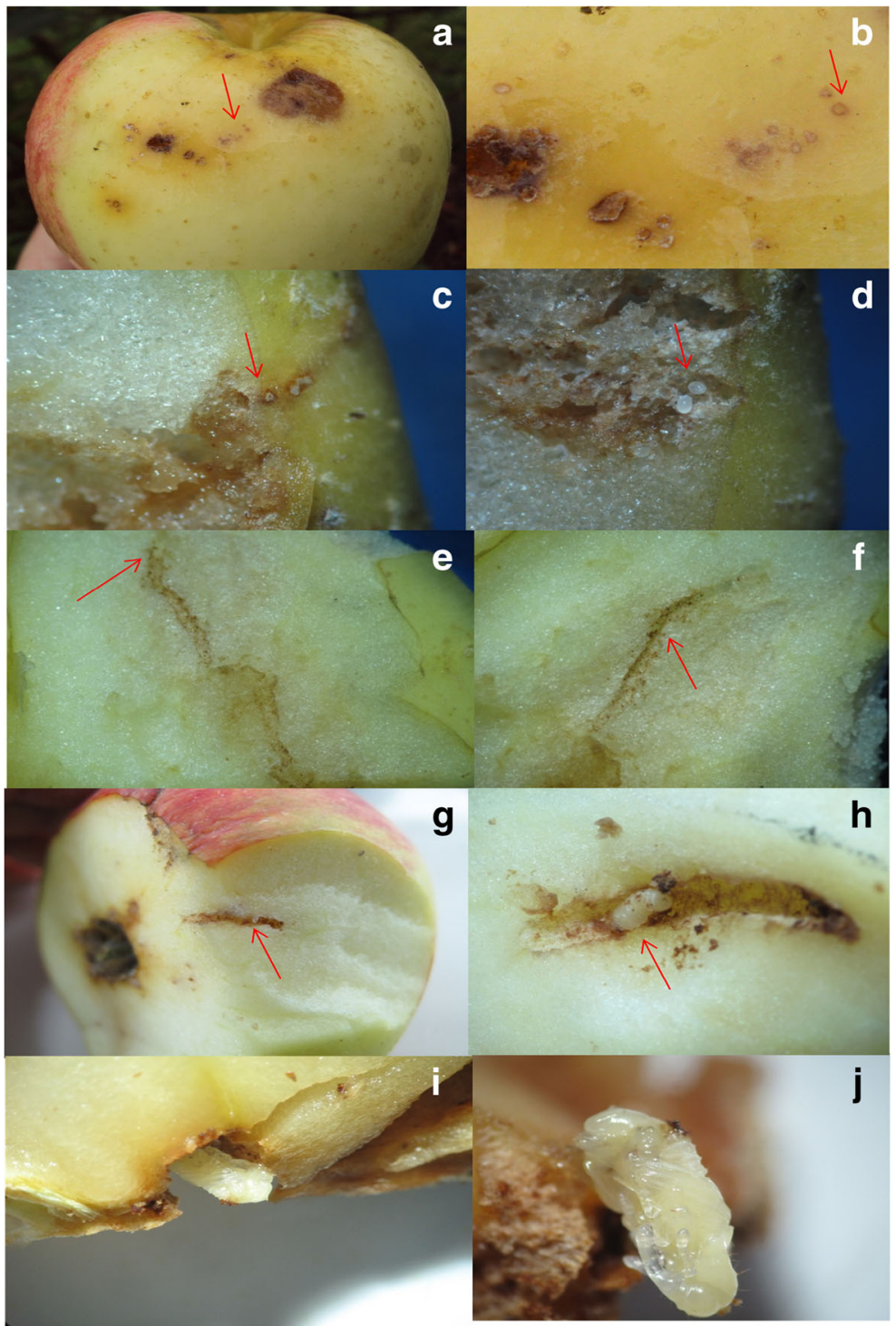

identification and differentiation of damage caused by feeding and oviposition. This fact may explain the nonobservance or report of oviposition in previous studies, which highlighted only damage caused by feeding (Lorenzato and Grellmann 1987; Salles 1998; Botton et al. 2005a, b; Hickel and Schuck 2005).

In peach and apple fruits, two eggs were laid per female on average, the number of eggs per hole ranged from one to three, and more common was just one egg per hole. In holes with two or three eggs, we observed that the first larva hatching fed on the other eggs. Such behavior can be understood as a form of competition for food substrate, similar to what occurs in corn grains where larvae practice cannibalism (Guedes et al. 2010) also described for S. granarius (Stubbs 1982).

The average of egg stage in peach fruits was $7.3 \pm$ $0.32 \mathrm{~d}$ (ranging from 5.0 to $10.0 \mathrm{~d}$ ), whereas in apple fruits, the period was $6.4 \pm 0.41 \mathrm{~d}$ (ranging from 4.0 to $11.0 \mathrm{~d})$. These periods were longer than in corn grains, which was $5.7 \pm 0.32 \mathrm{~d}$, which is the preferred host of $S$. zeamais, as well as in other cereals such as rice and wheat that have an average incubation period from 3.0 to $6.0 \mathrm{~d}$ (Rossetto 1969). The average duration of the larval stage in peach was $27.4 \pm 0.10 \mathrm{~d}$ (ranging from 24.0 and $30.0 \mathrm{~d}$ ), while in apple this duration was on 
average $28.2 \pm 0.56 \mathrm{~d}$ (ranging from 19.0 and $34.0 \mathrm{~d}$ ). In corn, the duration of the larval stage was $25.4 \pm 0.61 \mathrm{~d}$ (ranging from 18.0 and $29.0 \mathrm{~d}$ ).

The formation of galleries by larvae of $S$. zeamais in peach (Fig. 1c and d) and in apple (Fig. 2e and f) showed distinct behavior. Some larvae formed galleries in the center of the fruit, while others remained in the region just below the fruit exocarp. This shows that the larvae do not search for any specific part in the fruit (pulp or seeds) to form galleries and is contrary to behavior observed in tamarind fruits attacked by Sitophilus linearis (Coleoptera: Curculionidae) where adults penetrated the fruits and laid eggs in the seeds (Arthur and Arthur 2006).

The duration of the pupal stage in apple was $10.5 \pm$ $0.05 \mathrm{~d}$ while in peach, it was $12.7 \pm 0.02 \mathrm{~d}$, and in corn was $7.10 \pm 0.30 \mathrm{~d}$. In peach, we observed insects until adult stage (Figs. 1g, f, $2 \mathrm{i}$ and g), however, there was a dehydration process in the fruits (Fig. If and g), which probably affected the larval and pupal stages, allowing, thus, the emergence of only one adult (by the last two fruits). In apple, we observed the presence of dead adults, and this mortality was attributed to fruit rotting and subsequent accumulation of fluid in places where the pupae and adults stayed. Similarly, in peach, the pupae and adults were found in an inner region of the fruit, approximately $30 \mathrm{~mm}$ from the exocarp, hindering the immediate exit of the weevils of the fruits. In grains, due to the small size of the grains, the pupa was found near the exocarp, which facilitated the exit of adults after emergence, however, the behavior observed in grains indicates that post-emergence adults remain a period inside the grains (Longstaff 1981).

Based on our results and infestation behavior under field conditions, it is clear that in peach fruits, where the infestation period is three to four weeks before harvest (Nörnberg et al. 2013), no one would expect adults to emerge, because the egg-adult period is more than 40 days. While in apple trees where infestation is seven weeks (Nörnberg et al. 2013), larval development and emergence of adults would occur in the field.

Although the nutritional requirements of most phytophagous insects are similar, those that attack stored grains show a capacity, almost exclusive, to develop and reproduce in relatively dry foods (Lazzari and Lazzari 2009). However, the results of this study show that the species $S$. zeamais performs oviposition in fruits such as peach and apple, resulting in successful larval development and emergence of adults. This behavior may be an adaptation of this species to an alternate host, the fruits, during a period of the year when there is a lack of primary food (preferred hosts) in the region. In less suitable food, reproduction may occur, but the developmental period of immature forms may be longer and combinded with increased mortality. Under optimal conditions, mortality should be low (1-2\%), while in suboptimal conditions (extreme temperatures, humidity or qualitatively and quantitatively inadequate diet) mortality rates can reach $50-70 \%$ in each instar (Longstaff 1981). Thus, the distribution of several insect pest species is usually the result of the combination of environmental conditions or microclimate, the availability and quality of food, and the natural competition in different levels, allowing certain species to be abundant in conditions that are not completely optimal (Lazzari and Lazzari 2009).

Polyphagous insects may respond differently to genotypic variation of their hosts (Fry 1992) and the evolution of insect-host relationship can be significantly influenced by the plasticity of insects because the adaptive process to one host can result in decreased suitability for another host species. This phenomenon, known as trade-off in performance, may promote the selection of highly specialized insects to certain hosts (Ueno et al. 1997). If differences between populations of insects that can use different hosts are maintained by natural selection, new breeds or ecotypes may emerge (Via 1991). Thus, a good point is being made here to future research - it would be interesting to know whether, for example, an African or Asian strain of $S$. zeamais shows the same performance on apple or is less to use this host than the Brazilian strain observed here. This report may be also of great interest for ecological and evolutionary studies.

In agriculture, many pest-related problems are attributed to evolutionary problems (Via 1991), and the knowledge of how this evolution occurs in agricultural systems can facilitate the implementation of management strategies. In this sense, the results of this study are important evidences on the possibility of forming an ecotype of $S$. zeamais associated with fruits, requiring further research to better understand this relationship.

At last, the novelty that bring our results is in demonstrating that $S$. zeamais can complete a full life cycle using fresh fruits. Also, it is possible conclude that the damage in apple an peach does not only to the feed opportunistically by adults, but can be also due to oviposition and the development of immature stages. 
Acknowledgments We would like to thank Professor Dr. Germano Rosado Neto (Departamento de Zoologia, Universidade Federal do Paraná) to identified the specimens. Financial support provided in Brazil by Conselho Nacional de Desenvolvimento Científico e Tecnológico (CNPq), Fundação de Amparo à Pesquisa do Estado do Rio Grande do Sul (FAPERGS) and Deutscher Akademischer Austauschdienst (DAAD), Germany for scholarship granted. Thanks are also to Angelo Luis Ozelame for helping in the fruit samplings and bioassay perform.

\section{Compliance with ethical standards}

Conflict of interest The authors declare that they have no competing interests.

\section{References}

Adedire, C. O. (2001). Biology, ecology and control of insect pests of stored cereal grains. In T. I. Ofuya \& N. E. S. Lale (Eds.), Pests of stored cereals and pulses in Nigeria: Biology, ecology and control. Akure: Dave Collins Publications.

Arthur, V., \& Arthur, P. B. (2006). Controle de Sitophilus linearis (Herbst) (Coleoptera: Curculionidae) em Tamarindus indica através da radiação gama do Cobalto-60. Bolletin de Sanidad Vegetal de Plagas, 32, 121-124.

Botton, M., Lorini, I., Loeck, A. E., \& Afonso, A. P. S. (2005a). O gorgulho do milho Sitophilus zeamais (Coleoptera: Curculionidae) como praga em frutíferas de clima temperado. Bento Gonçalves: Embrapa Uva e Vinho (Circular técnica, 58). http://www.cnpuv.embrapa.br/publica/circular/cir058. pdf. Acessed 10 Apr 2017.

Botton, M., Lorini, I., Loeck, A. E., \& Afonso, A. P. S. (2005b). Ocorrência de Sitophilus zeamais (Coleoptera: Curculionidae) danificando a cultura da videira no Rio Grande do Sul. Neotropical Entomology. https://doi. org/10.1590/S1519-566X2005000200027

Corrêa, A. S., Oliveira, L. O., Braga, L. S., \& Guedes, R. N. C. (2013). Distribution of the related weevil species Sitophilus oryzae and S. zeamais in Brazil. Insect Science. https://doi. org/10.1111/j.1744-7917.2012.01559.x

Danho, M., Gaspar, C., \& Haubruge, E. (2002). The impact of grain quantity on the biology of Sitophilus zeamais Motschulsky (Coleoptera: Curculionidae): Oviposition, distribuition of eggs, adult emergence, body weight and sex ratio. Journal of Stored Products Research. https://doi. org/10.1016/S0022-474X(01)00027-3

Fry, J. D. (1992). On the maintenance of genetic variation by disruptive selection among hosts in a phytophagous mite. Evolution. https://doi.org/10.2307/2409823

Guedes, N. M. P., Guedes, R. N. C., Campbell, J. F., \& Throne, J. E. (2010). Contest behavior of maize weevil larvae when competing within seeds. Animal Behaviour. https://doi. org/10.1016/j.anbehav.2009.10.022

Halstead, D. G. H. (1963). The separation of Sitophilus zeamais Motschulsky and Sitophilus oryzae (L.) (Coleoptera
Curculionidae), with a summary of their distribution. Entomologist's Monthly Magazine, 99, 72-74.

Hickel, E. R., \& Schuck, E. (2005). Infestação e danos do gorgulho-do-milho em videira. Revista Agropecuária Catarinense, 18, 49-52.

Lazzari, S. M. N., \& Lazzari, F. A. (2009). Insetos-praga de grãos armazenados. In A. R. Panizzi \& J. R. P. Parra (Eds.), Bioecologia e nutrição de insetos (pp. 667-731). Brasília: Embrapa Informação Tecnologica.

Lecato, G. L., \& Flaherty, B. R. (1974). Description of eggs of selected species of stored-product insects (Coleoptera and Lepidoptera). Journal of the Kansas Entomological Society, 47(3), 308-317.

Longstaff, B. C. (1981). Biology of the grain pest species of the genus Sitophilus (Coleoptera: Curculionidae): A critical review. Protection Ecology, 3(2), 83-130.

Lorenzato, D., \& Grellmann, E. O. (1987). Resistência de maçãs, em dezesseis cultivares comerciais de macieiras (Malus domestica Bork), frente ao ataque do gorgulho do milho Sitophilus zeamais Motschulsky, 1855 (Coleoptera: Curculionidae). Agronomia Sulriograndense, 23(1), 3-10.

Murata, M., Imamura, T., \& Miyanoshita, A. (2008). Infestation and development of Sitophilus spp. in pouch-packaged spaghetti in Japan. Journal of Economic Entomology. https:// doi.org/10.1603/0022-0493(2008)101 [1006: IADOSS]2.0.CO;2

Nörnberg, S. D., Nava, D. E., Grützmacher, A. D., Bento, J. M. S., Ozelame, A. L., \& Hübner, L. K. (2013). Population dynamics and distribution of Sitophilus zeamais in peach and apple orchards. Pesquisa Agropecuária Brasileira. https://doi. org/10.1590/S0100-204X2013000400002

O'Donnell, A. E. (1967). The determination of larval instars of the Rice weevil Sitophilus oryzae (L.) (Coleoptera: Curculionidae) in wheat. Arkansas Academy of Science Proceedings, 21, 36-38.

Plarre, R. (2010). An attempt to reconstruct the natural and cultural history of the granary weevil, Sitophilus granarius (Coleoptera: Curculionidae). European Journal of Entomology. https://doi.org/10.14411/eje.2010.001

Rossetto, C. J. (1969). O complexo de Sitophilus spp., no Estado de São Paulo. Bragantia. https://doi.org/10.1590/S000687051969000100010 .

Salles, L. A. B. (1998). Principais pragas e seu controle. In C. A. B. Medeiros \& M. C. B. Raseira (Eds.), A cultura do pessegueiro (pp. 206-242). Brasília: Embrapa.

Stubbs, M. (1982). The influence of age of female at mating and duration of male presence upon the length of the pre-oviposition period and productivity of Sitophilus granarius (L.) (Coleoptera: Curculionidae) at $20^{\circ} \mathrm{C}$. Journal of Stored Products Research. https://doi.org/10.1016/0022-474X(82)90027-3

Ueno, H. N., Fujiyama, N., \& Katakura, H. (1997). Genetics basis for different host use in Epilachna pustulosa, a herbivorous lady bird beetle. Heredity. https://doi.org/10.1038/hdy.1997.42

Via, S. (1991). The genetic structure of host plant adaptation in a spatial patchwork: Demographic variability among reciprocally transplanted pea aphid clones. Evolution. https://doi. org/10.2307/2409692 